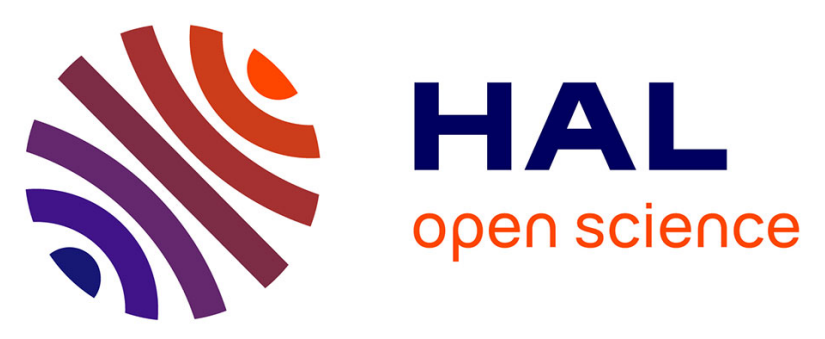

\title{
Mechanisms of Structural Reordering During Thermal Transformation of Aluminogermanate Imogolite Nanotubes
}

Geoffrey Monet, Stéphan Rouzière, Delphine Vantelon, Cristina Coelho Diogo, David Maurin, Jean-Louis Bantignies, Pascale Launois, Erwan Paineau

\section{To cite this version:}

Geoffrey Monet, Stéphan Rouzière, Delphine Vantelon, Cristina Coelho Diogo, David Maurin, et al.. Mechanisms of Structural Reordering During Thermal Transformation of Aluminogermanate Imogolite Nanotubes. Journal of Physical Chemistry C, 2021, 125 (22), pp.12414-12423. 10.1021/acs.jpcc.1c02852 . hal-03278914

\section{HAL Id: hal-03278914 https://hal.science/hal-03278914}

Submitted on 6 Jul 2021

HAL is a multi-disciplinary open access archive for the deposit and dissemination of scientific research documents, whether they are published or not. The documents may come from teaching and research institutions in France or abroad, or from public or private research centers.
L'archive ouverte pluridisciplinaire HAL, est destinée au dépôt et à la diffusion de documents scientifiques de niveau recherche, publiés ou non, émanant des établissements d'enseignement et de recherche français ou étrangers, des laboratoires publics ou privés. 


\title{
Mechanisms of Structural Reordering During Thermal Transformation of Aluminogermanate Imogolite Nanotubes
}

\author{
Geoffrey Monet, ${ }^{\dagger}$ Stéphan Rouzière, ${ }^{\dagger}$ Delphine Vantelon, ${ }^{\ddagger}$ Cristina Coelho Diogo, 9 \\ David Maurin, ${ }^{\S}$ Jean-Louis Bantignies, ${ }^{\S}$ Pascale Launois, ${ }^{*} \dagger$ and Erwan Paineau, ${ }^{*} \dagger$ \\ $\dagger$ †niversité Paris-Saclay, CNRS, Laboratoire de Physique des Solides, F-91405, Orsay, \\ France \\ $\ddagger$ Synchrotron SOLEIL, L'orme des Merisiers, Saint-Aubin, BP 48, 91192 Gif-sur-Yvette \\ Cedex, France \\ 【Sorbonne-Université, CNRS, Institut des Matériaux de Paris-Centre, FR2482, F-75005, \\ Paris, France \\ $\S$ Laboratoire Charles Coulomb, UMR 5221 CNRS-Université de Montpellier, F-34095 \\ Montpellier, France \\ E-mail: pascale.launois@universite-paris-saclay.fr: \\ erwan-nicolas.paineau@universite-paris-saclay.fr
}

\begin{abstract}
Metal oxide aluminosilicate and aluminogermanate nanotubes, called imogolite nanotubes, are custom made nanotubes with controlled diameter, morphology and organization. These nanotubes undergo major structural changes at high temperatures. Here, we report a complete analysis of the structural transformation of single and double-walled aluminogermanate nanotubes, organized or not in bundles, up to $800^{\circ} \mathrm{C}$. Complementary X-ray scattering and spectroscopy experiments were performed. The evolution of both $\mathrm{Al}$ and $\mathrm{Ge}$ atoms coordination during the transformation process was studied in-situ. Quantitative analysis of X-ray absorption spectra reveals that the dehydroxylation of nanotubes leads to intermediate stages of 'metaimogolite', which differ in the coordination of the aluminium atoms. A mechanism explaining the major structural reorganization is proposed based on atomic jump processes.
\end{abstract}

\section{Introduction}

Thermal treatment is one of the most commonly applied process to modify the structure, porosity and surface reactivity properties of aluminosilicate clay minerals. The structural transformation of these materials with temperature is usually split into three phases: ${ }^{1]}(i)$ dehydration stage, $(i i)$ dehydroxylation stage coupled with a significant modification of the crystalline structure and (iii) long-distance atomic re-organization and re-crystallization.

During the dehydroxylation stage, clay materials may proceed through intermediate and metastable stages, whose structure is sometimes only partially known even now. For instance, dehydroxylation of kaolinite, a dioctahedral clay mineral, induces the formation of metakaolin, ${ }^{215}$ which has valuable properties for catalysis, ${ }^{6}$ as binder in lightweight cements and concretes ${ }^{7]}$ or as precursor for zeolite synthesis. ${ }^{819}$ The formation of such intermediate phase is not limited to two-dimensional aluminosilicate clays. Similar structural evolution have 
been reported during heat treatment of halloysite nanotubes (rolled kaolinite sheet) and allophane nanospheres. $\frac{12}{}$ Transformation into crystalline mullite is observed at high temperature. 2 2|4|11|12

A very peculiar clay nanomaterial is imogolite. Imogolite nanotubes (INTs) were first discovered in soils. $\frac{13}{13}$ They are also readily synthesized with well-controlled diameter, adjustable morphology and rationally designed interface and organization. $\frac{1423}{23}$ These $(\mathrm{OH})_{3} \mathrm{Al}_{2} \mathrm{O}_{3} \mathrm{X}(\mathrm{R})$ (with $\mathrm{X}=\mathrm{Si}$ or $\mathrm{Ge} ; \mathrm{R}=\mathrm{OH}, \mathrm{CH}_{3} \ldots$ ) nanotubes are made of isolated tetrahedral $\left[(\mathrm{R}) \mathrm{XO}_{3}\right]$ units on the inner surface connected to a curved gibbsite-like octahedral framework on the outer surface $\left[\mathrm{Al}(\mathrm{OH})_{3}\right] \cdot \frac{.22|24| 25}{}$ They can form either individual single- (SW) or double-walled (DW) nanotubes of few nanometers in diameter (Figure 1). 26|27. In other clay nanomaterials such as kaolinite or halloysite, polymerized $\mathrm{SiO}_{4}$ tetrahedra form an interconnected layer with apical oxygen connected to the octahedral layer while they are isolated and inverted in imogolite structure. Tetrahedron orientation in INTs is thus exceptional for a clay mineral.
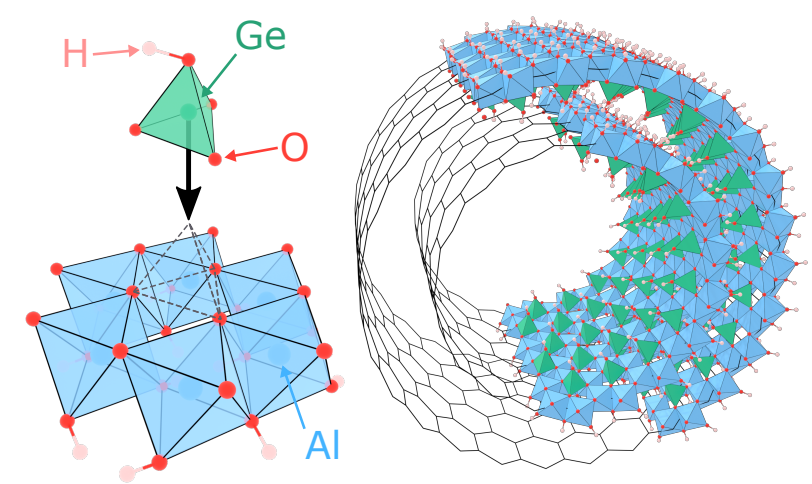

Figure 1: Polyhedral representation of a double-walled Ge-INT where $\mathrm{O}_{3} \mathrm{Al}(\mathrm{OH})_{3}$ blue octahedra are arranged to form a honeycomb network and green $\mathrm{O}_{3} \mathrm{GeOH}$ tetrahedra are placed right above each octahedral cavity.

The thermal stability of imogolite nanotubes has been addressed extensively since their discovery, ${ }^{28}$ highlighting the expected phase sequence with dehydration around $T \sim 120^{\circ} \mathrm{C}$ then dehydroxylation $\left(T=300-500{ }^{\circ} \mathrm{C}\right)$ of the nanotubes before transformation into mullite for temperatures above $900^{\circ} \mathrm{C} .13[29$ Like other clay nanomaterials, these nanotubes undergo major structural transformations during dehydroxylation stage. An amorphous phase was observed from X-ray scattering experiments on INT samples thermally treated at $350^{\circ} \mathrm{C}^{30}$ or around $500^{\circ} \mathrm{C}, \frac{29}{2}$ related to a probable collapse of the nanotube structure. ${ }^{31}$ Some studies proposed a mechanism based on the breakage of the nanotubes and the formation of a layer structure, ${ }^{32}$ in which however residual tubular structures could be retained. $\stackrel{33}{ }$ At a local level, solidstate nuclear magnetic resonance (NMR) experiments and density functional theory (DFT) simulations hinted important local modification

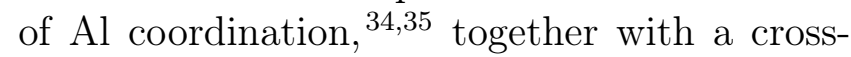
linking of Si tetrahedral sites. ${ }^{[36] 37}$ But a unified description of the thermally induced reorganization based on the whole set of available experimental data is still missing to date.

The interest of a 'metaimogolite' phase with appealing properties as those reported for metakaolinites or metahalloysites, $\stackrel{38 \mid 39}{\text { has led }}$ us to re-examine the effect of temperature on INTs. Most studies on the thermal transformation of imogolite nanotubes were performed on aluminosilicate INTs. Here, we focus on aluminogermanate analogues (Ge-INTs) because they can be synthesized $(i)$ in large quantities, 40 (ii) with one (SW Ge-INTs) or two walls (DW Ge-INTs) ${ }^{26}$ (iii) while controlling their organization as isolated or bundled nan-

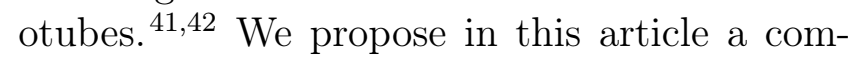
plete analysis of the thermally-induced structural changes of Ge-INTs. The evolution of the long-distance structure was investigated by in-situ and ex-situ X-ray scattering measurements. To go beyond, we applied an original approach including in-situ flyscan X-ray absorption (XAS) spectroscopy measurements, allowing us to follow the changes of both $\mathrm{Al}$ and $\mathrm{Ge}$ atoms coordination during the transformation process. Altogether, we evidence that from dehydration of the nanotube to its recrystallization in mullite form, the structure goes through three intermediate stages (stages I, II, III) for which the coordination of the aluminum atoms differs. In particular, we propose an original model based on atomic jump processes to explain the atomic rearrangement after dehydrox- 
ylation.

\section{Materials and Methods}

\section{Chemicals}

Aluminum perchlorate nonahydrate (Al$\mathrm{ClO}_{3} \cdot 9 \mathrm{H}_{2} \mathrm{O}$, ACS reagent, $\geq 98 \%$ ), anhydrous $\mathrm{NaOH}$ (ACS reagent, $\geq 97 \%$ ), urea $\left(\mathrm{CO}\left(\mathrm{NH}_{2}\right)_{2}\right.$, ACS reagent, $\left.\geq 99 \%\right)$ and tetraethoxygermanium (TEOG, $\mathrm{Ge}\left(\mathrm{OC}_{2} \mathrm{H}_{5}\right)_{4}$, ACS reagent, $\geq 99.5 \%$ ) were purchased from Sigma Aldrich. KBr (IR grade) was purchased from Merck. All products were used as received.

\section{Nanotube syntheses}

Aluminogermanate INTs were synthesized by the co-precipitation under vigorous stirring of an aluminum perchlorate solution and TEOG with an $[\mathrm{Al}] /[\mathrm{Ge}]$ ratio of 2 . SW Ge-INTs were synthesized with an initial aluminum concentration of $\mathrm{C}_{\mathrm{Al}}=1 \mathrm{~mol} . \mathrm{L}^{-1}$, followed by slow hydrolysis through the addition of a $\mathrm{NaOH}$ solution $\left(1 \mathrm{~mol} . \mathrm{L}^{-1}\right)$ until a hydrolysis ratio $\mathrm{R}_{[\mathrm{OH}] /[\mathrm{Al}]}$ of 2 is reached. The mixture was then aged for 5 days into an oven at $95^{\circ} \mathrm{C} . \underline{43}$ For DW Ge-INTs, a single-step procedure was applied as described elsewhere. ${ }^{40}$ In that case, TEOG was mixed together with an aluminum perchlorate solution $\left(\mathrm{C}_{\mathrm{Al}}=0.2 \mathrm{~mol} . \mathrm{L}^{-1}\right)$ and a urea solution up to a [urea]/[Al] ratio of 1 . The mixture was transferred in an autoclave and placed in an oven at $140{ }^{\circ} \mathrm{C}$ for 5 days.

\section{Samples preparation}

Suspensions were recovered at room temperature and subsequently dialyzed against ultrapure water (Spectra/Por, cut-off $10 \mathrm{kDa}$, Spectrum). Similar INTs samples have been characterized in our previous works, showing that both type of INTs have monodisperse diameters of 4.1 (SW) and $4.3 \mathrm{~nm}$ (DW) (one reports here their external diameters). ${ }^{43 / 44}$ The degree of nanotube organization can be easily controlled by varying the number of dialysis steps $x . \underline{41}$ For each nanotube morphology, two sets of suspensions have been prepared: $(i)$ $x=4$ to obtain imogolite bundles. These samples will be referred as $\mathrm{SW}_{\mathrm{b}}$ and $\mathrm{DW}_{\mathrm{b}}$ in the following. ( $i i) x=9$ for fully dispersed SW or DW Ge-INTs. The four suspensions were left to evaporate at room temperature during one week in polystyrene weighing dishes to get selfsupported films. $\frac{45}{4}$ A part of the obtained films were stored as such for in-situ synchrotronbased experiments while the rest was milled in an agate mortar to obtain a fine powder.

Thermogravimetric analyses (TGA) were carried out (TGA Q50, TA Instruments) by heating $20 \mathrm{mg}$ of powder sample under $\mathrm{N}_{2}$ gas flux with a temperature ramp of $10^{\circ} \mathrm{C} \cdot \mathrm{min}^{-1}$. 46

Series of powder samples were annealed in quartz crucibles at defined temperature (300, $400,500,600,700,800,900$ and $1000^{\circ} \mathrm{C}$ ) for $2 \mathrm{~h}$ in a muffle furnace (Thermolyne Furnace 6000) under air atmosphere prior to use for ex-situ experiments performed at room temperature.

\section{Ex-situ experiments}

\section{Wide-Angle X-ray scattering}

Powder samples were filled into borosilicate capillary tubes (WJM-Glas/Müller GmbH, $\mathrm{DE}$ ) of $1 \mathrm{~mm}$ diameter and flame-sealed. WideAngle X-ray scattering (WAXS) measurements were carried out on a $\mathrm{Cu}$ rotating anode generator (Rigaku, Corporation, Japan), providing a monochromatic beam with incident wavelength $\lambda=1.5418 \AA$ after confocal parabolic $\mathrm{W} / \mathrm{Si}$ multilayer mirrors. Experiments were performed in a vacuum chamber to optimize the signal over background ratio. The scattered intensity was collected on a large cylindrical image plate placed at a sample-to-detector distance of $104.8 \mathrm{~mm}$. Pixels counts were angularly summed and intensity versus wave-vector $Q$ curves were thus obtained $(Q=4 \pi / \lambda \sin \theta$, where $2 \theta$ is the scattering angle). Values as large as $Q=8 \AA^{-1}$ are reached. Intensity is corrected for polarization and geometrical factors.

\section{Infrared spectroscopy}

Fourier transform infrared (FT-IR) spectroscopy measurements were performed using 
a Bruker Tensor 27 spectrometer. The measurements were performed in the mid-infrared region $\left(400-4000 \mathrm{~cm}^{-1}\right)$ in the transmission configuration using $\mathrm{KBr}$ pellets $(\sim 1.3 \mathrm{mg}$ powder INT sample/300 mg KBr), prepared under 7-tons pressure. Prior to IR experiments, the pellets were dried at $100^{\circ} \mathrm{C}$ for about $20 \mathrm{~h}$, to reduce the levels of adsorbed water. The IR spectra were collected at room temperature by averaging 128 scans with a spectral resolution of $4 \mathrm{~cm}^{-1}$.

\section{Nuclear Magnetic Resonance}

Solid-state magic-angle spinning (MAS) NMR experiments were performed on a Bruker AVANCE III 700 spectrometer based on a $16.4 \mathrm{~T}$ superconducting solenoid operating at $\nu_{0}\left({ }^{27} \mathrm{Al}\right)=182.47 \mathrm{MHz}$ using commercial double resonance Bruker MAS probes. Powder samples prepared at room temperature and at $\mathrm{T}=800^{\circ} \mathrm{C}$ were transferred to $\mathrm{ZrO}_{2}$ rotors with an outer diameter of $2.5 \mathrm{~mm}$ and were heated at $200{ }^{\circ} \mathrm{C}$ to remove adsorbed water. For measurements, the rotors were spinned at a MAS rate of $25 \mathrm{kHz}$. All ${ }^{27} \mathrm{Al}$ ( $\left.\operatorname{spin} l=5 / 2\right)$ MAS NMR spectra were obtained by using short pulses $(<\pi / 8)$ for quantitative purposes. Nutation curves were first established by using a solution of $1 \mathrm{M} \mathrm{Al}\left(\mathrm{NO}_{3}\right)_{3}$. All decomposition of spectra were performed using the DMfit software. 47

\section{In-situ synchrotron-based experi- ments}

Combined in-situ X-ray scattering (XRS) and X-ray absorption spectroscopy (XAS) experiments were carried out on the DiffAbs beamline at the synchrotron SOLEIL. The experiments were performed at the Ge K-edge $\left(E_{0}=11.1 \mathrm{keV}\right)$ using a $\mathrm{Si}(111)$ double crystal monochromator. Film samples were mounted in a furnace (DHS900, Anton Paar GmbH) operating in air from room temperature to $700{ }^{\circ} \mathrm{C}$. XRS measurements were first performed in a continuous way (flyScan mode), at a heating rate of $2{ }^{\circ} \mathrm{C} \cdot \mathrm{min}^{-1}$, up to temperature steps at which XAS measurements were performed. A CCD camera (SX- 165 model, Rayonix, USA) was used to measure XRS patterns in the $Q$ range $\left[0.1-4 \AA^{-1}\right]$, in reflection geometry (vertical sample surface). A SDD detector allowed recording XAS spectra in fluorescence mode within the same experimental setup configuration. Extended X-ray absorption fine structure (EXAFS) oscillations were extracted after standard procedures using the ATHENA software package, $\stackrel{48}{4}$ and were compared to simulations performed with the IFEFFIT code ${ }^{48}$.

X-ray absorption spectra at the $\mathrm{Al} \mathrm{K-edge}$ were collected at the LUCIA beamline of synchrotron SOLEIL. ${ }^{49}$ The X-ray beam was monochromatised with a $\operatorname{KTP}(011)$ double crystal and beam focalization was ensured by Kirkpatrick-Baez mirrors, allowing a beam size of $3 \times 3 \mathrm{~m}^{2}$ on the sample. The energy of the monochromator was calibrated on the first peak of the first derivative of an $\mathrm{Al}$ foil spectrum at $1559.6 \mathrm{eV}$. INT film samples were placed in a primary vacuum chamber equipped with a dedicated home-made oven. XANES measurements were performed by collecting the fluorescence spectra continuously while increasing the temperature until $800^{\circ} \mathrm{C}$, with a ramp of $5^{\circ} \mathrm{C} \cdot \mathrm{min}^{-1}$. XANES spectra range from $1550 \mathrm{eV}$ to $1700 \mathrm{eV}$ with an energy step of $0.2 \mathrm{eV}$ and a counting time of $0.3 \mathrm{~s}$. Moreover, in order to highlight the kinetics of the transformation, constant temperature stages have been made at 500, 700 and $800{ }^{\circ} \mathrm{C}$ where data were collected for about 1 hour. XANES data were obtained after performing standard procedures for pre-edge subtraction, normalization and self-absorption correction using the ATHENA software package. ${ }^{48}$ The fit of the XANES curves was done on the $1560-1580 \mathrm{eV}$ region using the Python lmfit library. .50

\section{Results and discussion}

We performed the experiments on four different samples (SW or DW nanotubes, isolated or in bundles). However, results were quite close. Thus only the results obtained for DW nanotubes are presented in the main part of the article, the others data being provided in Supplementary Information. 


\section{Thermogravimetric analysis}

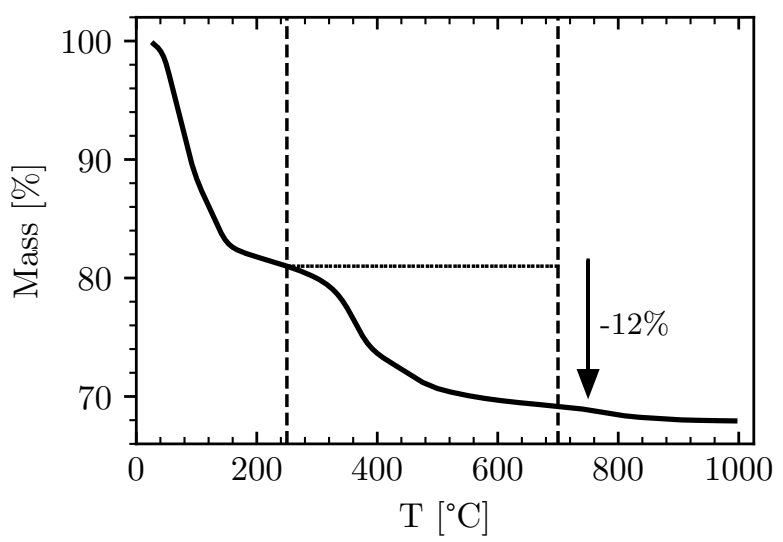

Figure 2: Typical TGA curve obtained for a powder of DW INTs.

Mass loss of DW sample as a function of temperature is shown in Figure 2. All samples $\left(\mathrm{SW}, \mathrm{SW}_{\mathrm{b}}, \mathrm{DW}\right.$ and $\left.\mathrm{DW}_{\mathrm{b}}\right)$ present similar TGA curves (Figure S1). The first mass loss, below $200^{\circ} \mathrm{C}$, is due to the desorption of water loaded inside and between aluminogermanate nanotubes walls. ${ }^{43|51| 52} \mathrm{~A}$ second mass loss is evidenced between 300 and $500{ }^{\circ} \mathrm{C}$, which we mainly attribute to the dehydroxylation of the INT structure. 33151 Indeed, corresponding mass losses, calculated as the difference between masses at $250{ }^{\circ} \mathrm{C}$ and $700^{\circ} \mathrm{C}$ normalized to the mass at $700{ }^{\circ} \mathrm{C}$, are found to be equal to $12 \%, 13 \%, 11 \%$ and $10 \%$ for $\mathrm{DW}, \mathrm{DW}_{\mathrm{b}}$, $\mathrm{SW}$ and $\mathrm{SW}_{\mathrm{b}}$ samples respectively. Thermal decomposition of remaining perchlorate ions of the starting precursors used in the synthesis occurs in the same temperature range, $\underline{33}$ but their contribution remains negligible. Indeed, the dehydroxylation relation $\mathrm{GeAl}_{2} \mathrm{O}_{7} \mathrm{H}_{4}$ $\longrightarrow \mathrm{GeAl}_{2} \mathrm{O}_{5}+2 \mathrm{H}_{2} \mathrm{O}$ leads to a mass loss of $15 \%$ after the release of water molecules. Our measured mass losses thus appear compatible with a complete dehydroxylation process, similar to the one observed in kaolinite or halloysite. ${ }^{2|4| 11}$ The dehydroxylation process of imogolite can be split into a part corresponding to the outer wall $(\mathrm{OH})_{3} \mathrm{Al}_{2} \mathrm{O}_{1.5} \longrightarrow$ $\mathrm{O}_{1.5} \mathrm{Al}_{2} \mathrm{O}_{1.5}+1.5 \mathrm{H}_{2} \mathrm{O}$, and to the inner wall $\mathrm{O}_{1.5} \mathrm{Ge}(\mathrm{OH}) \longrightarrow \mathrm{O}_{1.5} \mathrm{GeO}_{0.5}+0.5 \mathrm{H}_{2} \mathrm{O}$ of the nanotube. Thus, the dehydroxylation quanti- fied by the TGA will result in a loss of 1.5 external and 0.5 internal $\mathrm{OH}$ groups. Presumably, this would be associated with the formation of Ge-O-Ge bridging to maintain 4 oxygens around the germanium atoms as it has been shown for silicium-based imogolite nanotubes. 34

\section{Phase transformation in mullite- type compound}

X-ray scattering is a powerful tool for investigating the structure of imogolite nanotubes. ${ }^{22}$ Figure 3 and Figure S2 present the evolution of the WAXS diagrams of powder samples of DW and SW INTs, annealed ex-situ up to $1000^{\circ} \mathrm{C}$.

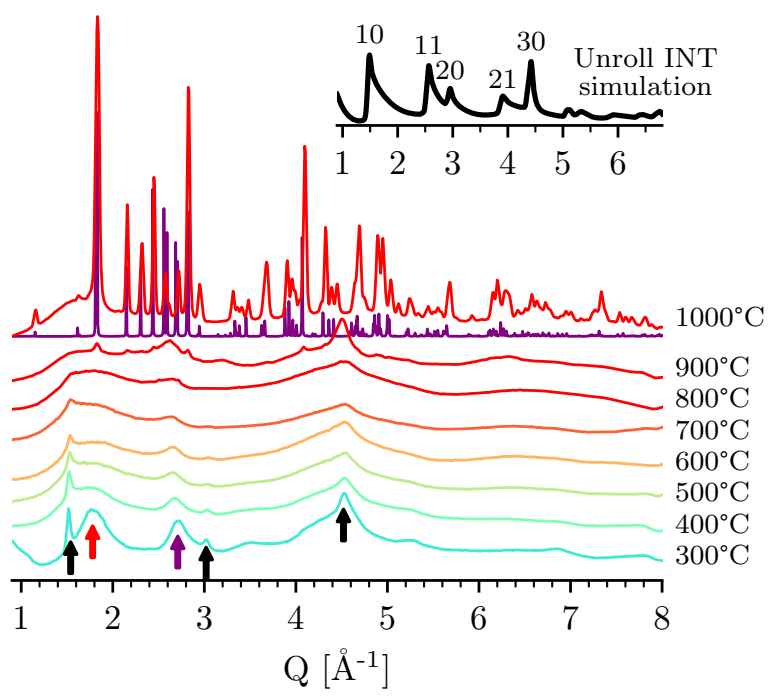

Figure 3: Wide angle X-ray scattering diagrams for powder samples of DW INT, annealed exsitu up to $1000^{\circ} \mathrm{C}$. Purple diagram is computed from a Ge-mullite structure provided by Voll et al. $\stackrel{53}{5}$ The inset shows the calculated X-ray scattering diagram of an unrolled imogolite nanotube. Arrows point towards modulations of the form factor of the nanotubes, as discussed in the text.

At room temperature, the diagrams present (i) broad oscillations due to the finite radial dimension of the nanotubes (red and purple arrows in Figure 3 and Figure S2) and (ii) welldefined peaks around $\mathrm{Q}=1.5,3$ and $4.5 \AA^{-1}$ 
(black arrows). The latter come from the long range periodic order along the nanotube axis. The period is found to be around $8.6 \AA^{-1}$ for both SW and DW INTs ${ }^{52}$.

The evolution of the nanotube period with the temperature will be discussed in more details when presenting in-situ X-ray scattering experiments. However, some conclusions can already be drawn here. For this purpose, we calculated the diffraction diagram of an unrolled imogolite nanotube (inset in Figure 31). Indexes refer to the hexagonal unit cell of the unrolled nanotube (hexagons are drawn in black in Figure 1). The broad modulation around $1.8 \AA^{-1}$ (red arrow in Figure 3 and Figure S2) is absent in the diffraction diagram of this flat structure. Yet, this component is very present when simulating the X-ray diffraction diagram of an imogolite nanotube. ${ }^{522}$ It follows from figures 3 and S2 that such modulation is strongly affected when the temperature increases, while diffraction features characteristic of the hexagonal network persist up to $800^{\circ} \mathrm{C}$. It can thus be inferred than the hexagonal local atomic organization is relatively well maintained upon dehydroxylation, while the tubes are no more circular. Such results had never been reported before.

Above $900{ }^{\circ} \mathrm{C}$, WAXS diagrams of SW and DW INTs are dramatically modified. They exhibit diffraction peaks characteristic of the Ge-mullite structure proposed by Voll et al. (Figure 33) ${ }^{53}$ Although the transformation of alumino-silicate nanotubes into mullite at high temperature is well known,,$\frac{13}{3}$ this is the first proof that heat-treated $\mathrm{GeOH}$ imogolite nanotubes can form Ge-mullite. As evidenced from TGA measurements (Figure 2), formation of mullite is achieved without any mass loss.

The phase transformation of GeOH INTs has also been investigated by infrared spectroscopy (Figure 4 and Figure S3). At room temperature (RT), the IR spectrum of DW imogolite nanotubes presents $\mathrm{Ge}-\mathrm{O}$ stretching modes, with a characteristic doublet at $805 / 830 \mathrm{~cm}^{-1}$ (blue arrows in Figure 4) and its shoulder at $915 \mathrm{~cm}^{-1}$, along with a broad absorption band around $555 \mathrm{~cm}^{-1}$ due to $\mathrm{Al}-\mathrm{O}$ stretching modes. ${ }^{261445154}$ The $\mathrm{OH}$ bending vibration of water molecules is observed at $1635 \mathrm{~cm}^{-1}$ while the broad band near $3000-3800 \mathrm{~cm}^{-1}$ is a combination of $\mathrm{OH}$ stretching vibrations of INTs, stretching modes of $\mathrm{H}_{2} \mathrm{O}$ as well as an overtone of the $\mathrm{OH}$ bending mode. 55

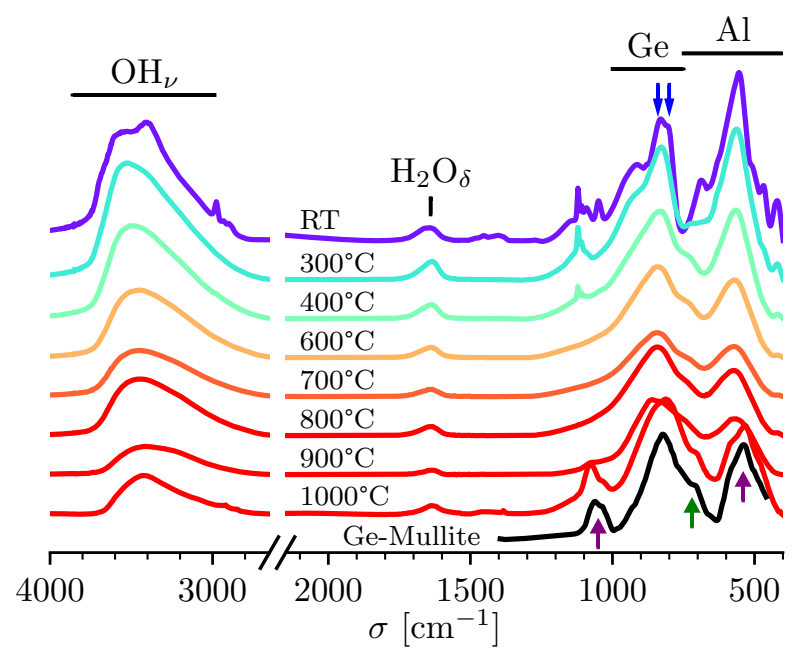

Figure 4: IR absorbance spectra obtained from powders of DW INT, annealed ex-situ up to $1000^{\circ} \mathrm{C}$. The black curve corresponds to synthetic Ge-mullite, adapted from ref.56. The blue arrows show a characteristic doublet of the Ge-O stretching vibrations in imogolite nanotubes. The purple and green arrows highlight vibration modes that appear after heat treatment above $900{ }^{\circ} \mathrm{C}$ (see the text).

Significant modifications in the vibrational characteristics of INTs are observed with the heat treatment (Figure 4). Between $300^{\circ} \mathrm{C}$ and $900^{\circ} \mathrm{C}$, the stretching modes associated to aluminum atoms decrease progressively and even vanish due to strong modification of the local structure in the nanotubes. For SW nanotubes, the stretching modes associated with aluminum and the Ge-O stretching vibrations appear to evolve in a similar way (Figure S3). Looking back at DW INTs, we also evidence that the GeO stretching contribution shifts to a lower frequency at $1000^{\circ} \mathrm{C}$, while new vibrations modes are observed at 1080 and $540 \mathrm{~cm}^{-1}$ (purple arrows in Figure 4). The peak at $1080 \mathrm{~cm}^{-1}$ can be assigned to the stretching vibration of Ge-OGe bonds in the mullite structure. ${ }^{56}$ More interestingly, the presence of a significant vibrational contribution at $750 \mathrm{~cm}^{-1}$ (green arrow) should 
be mentioned since it is related to bending vibrations of the tetrahedral $\mathrm{TO}_{4}$ units in the mullite framework. ${ }^{10156}$ The occurrence of this peak upon dehydroxylation, for both SW and DW INTs, indicates that important changes affect the coordination of $\mathrm{Al}$ atoms well before re-crystallization in mullite-type compound.

Based on these first insights obtained thanks to ex-situ X-ray sacattering and IR experiments, in-situ experiments have been performed to address the mechanisms of structural transformations of $\mathrm{GeOH}$ nanotubes above $300^{\circ}$ and before the transformation to mullite, leading to the formation of one or several 'metaimogolite' stages.

\section{Structural investigation of 'meta- imogolite'}

Synchrotron experiments were performed on the DiffAbs beamline, which offers the possibility to combine X-ray scattering and X-ray absorption spectroscopy measurements, using the same setup and on the same area of the sample. Figure 5 and Figure S5 show the evolution of XRS diagrams upon heating for all samples.

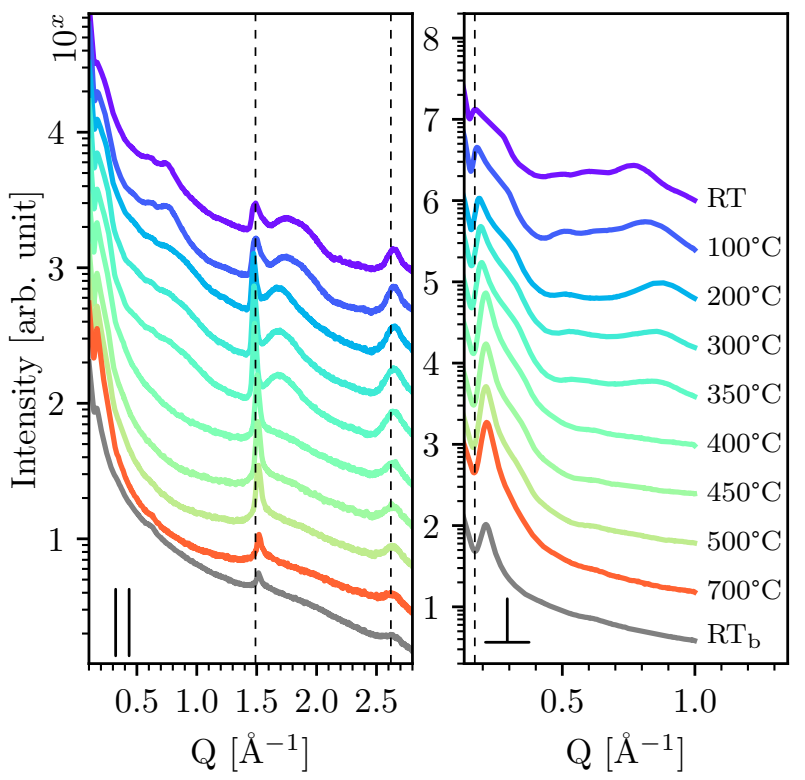

Figure 5: X-ray scattering diagrams measured in parallel (left panel) and perpendicular (right panel) directions to the self-supporting film of DW INTs. XRS measurements were carried out in-situ heat treatment up to $700{ }^{\circ} \mathrm{C}$. The measurement labelled "RT $\mathrm{b}_{\mathrm{b}}$ (grey curve) refers to the heat-treated sample brought back to room temperature. Curves have been translated for sake of clarity.

In-situ XRS measurements were performed on self-supporting films where the nanotube axes are preferentially in plane. Two non-equivalent X-ray scattering directions are investigated: $(i)$ the direction perpendicular to the film, which provides information on the radial direction of the nanotubes as well as the organization of the nanotubes into bundles; (ii) a direction parallel to the film, which gives structural features along all the directions of the nanotubes (see Figure S4). For instance, peaks related to the period along the nanotubes are only observed in parallel direction. Dashed lines in Figures 5 and S5 are guide for the eye.

The period is calculated from the position of the inflection point of the peak around $1.5 \AA^{-1}$, which presents an asymmetric shape as expected for low-dimensional periodic structures. 22152 It remains unchanged up to $\mathrm{T}=$ $400{ }^{\circ} \mathrm{C}$ but it shifts towards larger wave-vector values when the temperature is increased. The modulation around $2.5 \AA^{-1}$, which can be re- 
lated to local hexagonal order (see inset in Figure 3) also shifts towards larger-Q values. The period decrease $(\sim-0.3 \AA)$ corresponds to a shrinking of the nanotubes along their long axis during the dehydroxylation stage. The modulation around $1.8 \AA^{-1}$ as well as the oscillations for wave-vectors below $1 \AA^{-1}$ are strongly modified at $\mathrm{T}=400^{\circ} \mathrm{C}$. The decrease of the first modulation has already been discussed in terms of radial distortion of the nanotubes. The latter modulations can be calculated within an homogeneous approximation ${ }^{43157}$ and they are also associated with the circular tubular shape. In particular, for DW nanotubes, modulations between $0.5 \AA^{-1}$ and $1 \AA^{-1}$ are associated to the interferences between the two nanotube walls. Their disappearance at $400^{\circ} \mathrm{C}$ indicates that the two walls are no more concentric and circular. When nanotubes form bundles, XRS diagrams display relatively narrow peaks below $1 \AA^{-1}$ indexed according to a twodimensional hexagonal lattice (see red arrows in Figure S5). ${ }^{41}$ As evidenced from our experiments, the bundles peaks also disappears when the dehydroxylation starts at $\mathrm{T}=300^{\circ} \mathrm{C}$. All these features point towards radial distortions of the nanotubes.

At $700^{\circ} \mathrm{C}$, a small offset of the first scattering peak to $Q_{1} \sim 0.15 \AA^{-1}$ (Figure 5 and S5) is evidenced in all samples. This first modulation of the form factor is still rather intense so that their tubular shape is found to be more or less preserved at $700^{\circ} \mathrm{C}$. The related distance is $d$ $\sim 42 \AA$ in direct space, close to the value of the outer diameter of both SW and DW nanotube. It may also be noted that for SW and DW bundles, very small intensity peaks are observed at $Q=2 Q_{1}$ and at $Q=3 Q_{1}$ at high temperature (see blue arrows in Figure S5). Similar observations were reported for aluminosilicate imogolite nanotubes. $\frac{3133}{31}$

The thermal transformation of nanotubes above $\mathrm{T}=500^{\circ} \mathrm{C}$ is irreversible as shown from the XRS diagrams obtained after return to room temperature $\left(\mathrm{RT}_{\mathrm{b}}\right.$ curves in Figure 5 and S5). Reversibility can only be achieved if the dehydroxylation is not complete. 31134

\section{Evolution of the atomic local order- ing}

To understand how heat-treatment affects the atomic local ordering, we investigated the different samples by using complementary local probes. In a first step, we performed complementary ${ }^{27} \mathrm{Al}$ NMR experiments on GeOH nanotubes before and after ex-situ thermal treatment $\left(\mathrm{T}=800^{\circ} \mathrm{C}\right)$ to identify the different $\mathrm{Al}$ coordination environments.

${ }^{27} \mathrm{Al}$ MAS NMR spectra of imogolite nanotubes before heat treatment (Figure 6a and Figure S6) present a main component at $8.8 \mathrm{ppm}$ corresponding to octahedrally coordinated $\left(\mathrm{Al}^{\mathrm{VI}}\right)$ atoms. $\frac{15158}{1 n}$ the case of $\mathrm{SW}$ and $\mathrm{SW}_{\mathrm{b}}$ samples, this peak presents a chemical shielding anisotropy with a weak contribution at $6.6 \mathrm{ppm}$. This contribution corresponds to distorted octahedral environments $\mathrm{Al}_{\mathrm{d}}^{\mathrm{VI}}$, probably due to wall defects as evidenced previously for aluminosilicate SW INTs. ${ }^{[59}$ In addition, the ${ }^{27} \mathrm{Al}$ MAS NMR spectrum of $\mathrm{SW}_{\mathrm{b}}$ nanotubes display a third minor component $\left(\mathrm{Al}^{\mathrm{VI} *}\right)$ located at $\sim 0 \mathrm{ppm}$, which corresponds to unreacted $\mathrm{Al}$ monomers and represents less than $2 \%$ of the $\mathrm{Al}$ content. 15 


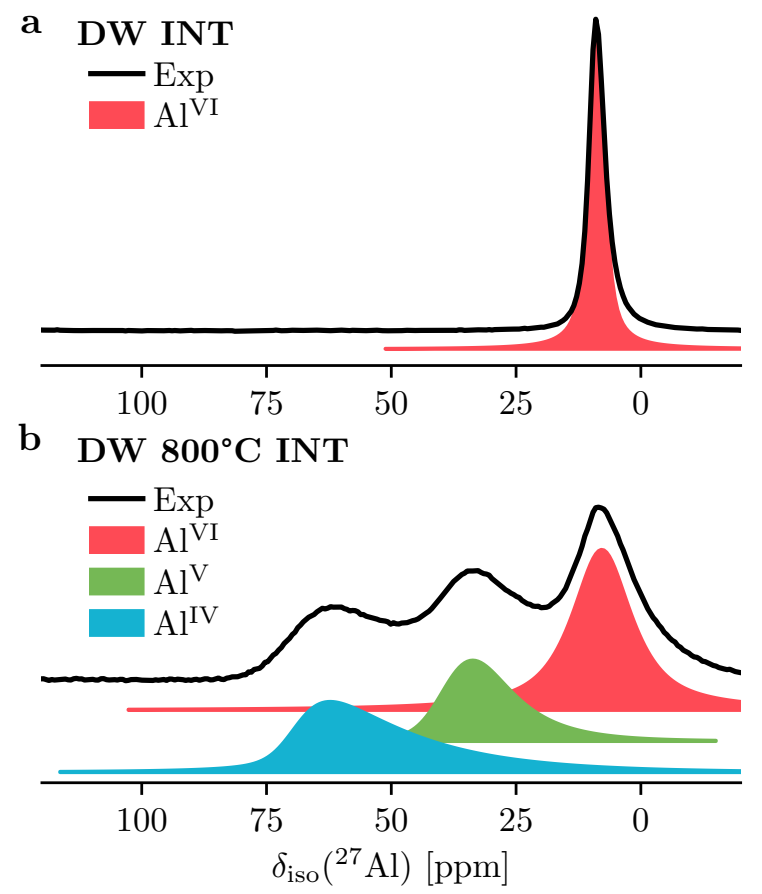

Figure 6: ${ }^{27} \mathrm{Al}$ MAS NMR spectra for a powder of DW INT (a) before and (b) after heattreatment at $800^{\circ} \mathrm{C}$. Coloured curves correspond to the deconvolution of the experimental black curve.

After heat-treatment at $800^{\circ} \mathrm{C}$, the samples show two new well-resolved resonances at $70 \mathrm{ppm}$ and $39 \mathrm{ppm}$, related to tetrahedral $\left(\mathrm{Al}^{\mathrm{IV}}\right)$ and pentahedral $\left(\mathrm{Al}^{\mathrm{V}}\right)$ environment, respectively (Figure $6 \mathrm{~b}$ and Figure S7). $\underline{32[35] 60 \mid 61}$ Furthermore, the chemical shift $\delta_{\text {iso }}$ of $\mathrm{Al}^{\mathrm{VI}}$ environment decreases for SW (7.4 ppm) and DW INTs $(7.8 \mathrm{ppm})$. A similar effect was observed for heat-treated aluminosilicate SW INTs, $\stackrel{35}{ }$ which suggests structural strain with increasing the temperature. However, all these peaks are distributed along the chemical shift line in the ${ }^{27} \mathrm{Al}$ MQMAS spectra with a limited quadrupole-induced shift (Figure S8), allowing one to rule out the presence of multiple Al sites associated with each coordination. The release of hydroxyl groups between 300 and $500{ }^{\circ} \mathrm{C}$ implies a decrease of the coordination of $\mathrm{Al}$ atoms. 2 [2]32]34/35 The proportion of the different environments around aluminum atoms has been evaluated from a fit of the different components present in the NMR spectra (see Table S1 and Table S2). However, one cannot ex- clude the possibility of partial rehydroxylation and/or atomic re-arrangement during the cooling step of the samples between heat treatment and NMR measurements.

We investigated in-situ the evolution with temperature of the atomic local ordering thanks to X-ray absorption spectroscopy. Figure $7 \mathrm{~A}$ and Figure S9 show the variation of the Fourier transform of the $k$-weighted EXAFS obtained at the Ge K-edge as a function of the temperature. It was measured in conjunction with the X-ray scattering experiments presented previously. The evolution in temperature highlights a decrease in amplitude of the first oscillation combined with a strong attenuation and shift of oscillations beyond $R=2 \AA$. The intermediate curves reveal that the effect of heat-treatment on the atomic coordination of Ge atoms is a continuous process. 

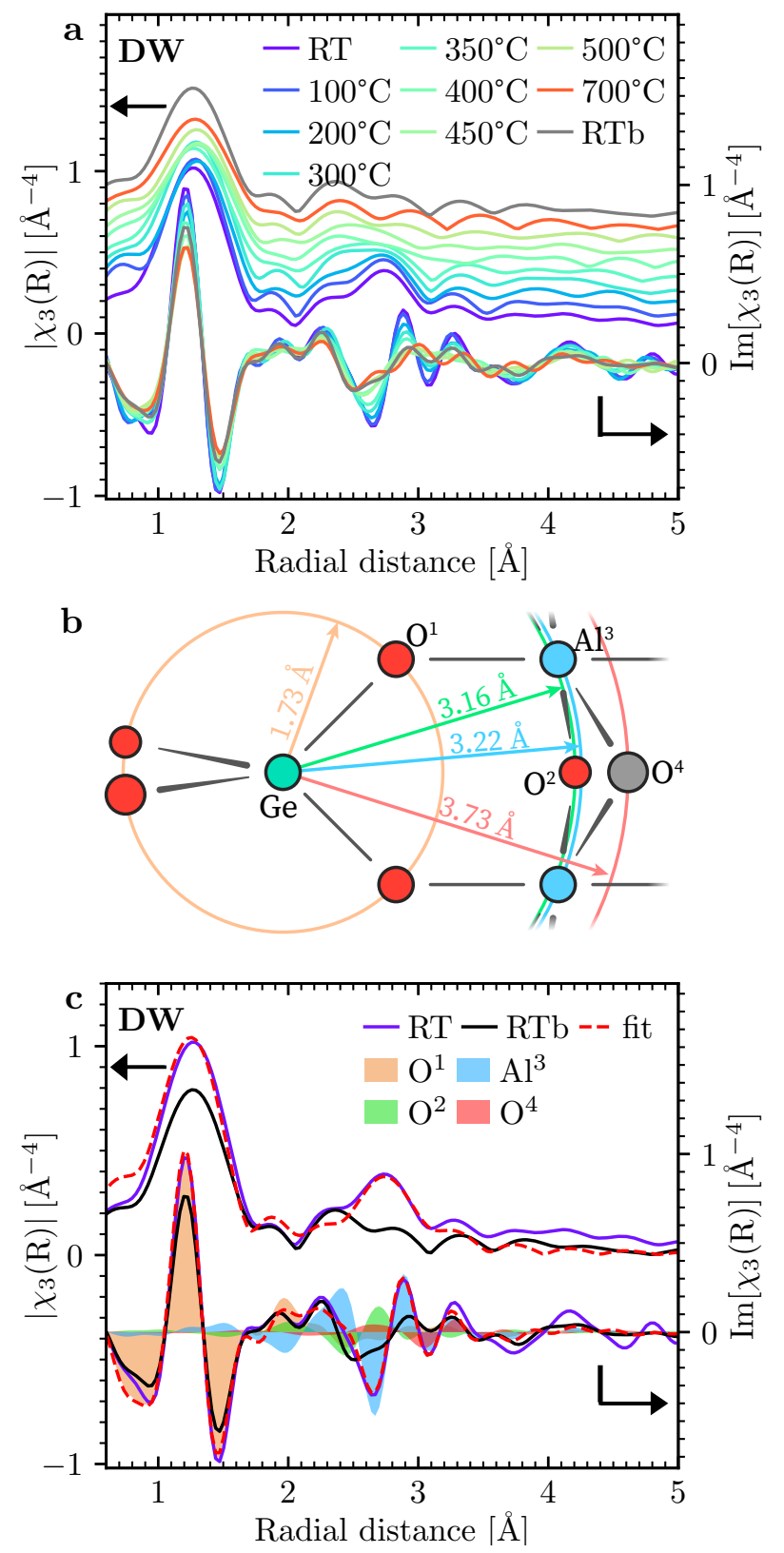

Figure 7: (a) Magnitude (above and shifted for sake of clarity) and imaginary (bellow) part of the Fourier transform (not corrected form phase shift) of the EXAFS $\chi_{3}(R)$ function collected at the Ge K-edge and for a DW INT powder heated in-situ. (b) Schematic representation of the first four coordination spheres around the scattering atom (Ge). (c) Comparison of EXAFS spectra for unheated INTs (RT) and heattreated sample brought back to room temperature ( $\mathrm{RTb}$ ) and contribution of the different atomic shells. Red curve corresponds to the best fit of unheated sample.

EXAFS data of the different samples are rather similar, due to their comparable lo- cal structure. Therefore, we started from the imogolite atomic structure inferred from previ-

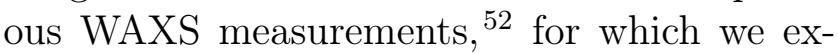
tracted the backscattering paths. Figure $7 \mathrm{~b}$ illustrates the first four atomic shells around Ge atoms. The backscattering paths were refined to adjust the calculated curves with the experimental data. Fit of the EXAFS curve for unheated INTs allowed us to determine to which atomic shell each oscillation corresponds (Figure 7c and fit parameters in Table S3). This refinement highlights: (1) a first coordination sphere composed of 4 oxygen atoms $\left(\mathrm{O}^{1}\right)$ and (2) a second coordination sphere composed of 3 oxygen atoms $\left(\mathrm{O}^{2}\right), 6$ aluminum atoms $\left(\mathrm{Al}^{3}\right)$ and 3 external oxygen atoms $\left(\mathrm{O}^{4}\right)$. The decrease of the first atomic shell contribution after heat treatment for $\mathrm{RT}_{\mathrm{b}}$ curve is limited and it may be related to some static disorder. Ge tetrahedral sites are preserved along the thermal decomposition of imogolite nanotubes. Although the TGA results indicate a complete deshydroxylation, which may be associated with a condensation of Ge atoms with oxygen bridges, as suggested previously for Sibased imogolite nanotubes,, 32134 we do not detect an increase in amplitude of the EXAFS function in second atomic shell of germanium atoms.

On the contrary, the amplitude of EXAFS oscillations are greatly reduced beyond $2 \AA$. This could be explained by a significant increase of structural disorder starting from the second sphere of coordination. There would be an important spread in the Ge-Ge distances associated with oxygen bridges and a rearrangement of the $\mathrm{Al}$ atoms with regard to the Ge ones (see blue area in Figure 7k). A further explanation for the reduction of the EXAFS amplitude around $2.7 \AA$ might be that the signal from $\mathrm{Al}$ atoms (blue area) is in phase opposition with the signal coming from Ge-O-Ge bridges as illustrated in Figure S10.

To complete this investigation, we report on the first in-situ investigation of XAS Al K-edge during the thermal transformation of imogolite nanotubes. Flyscan mode allows us to follow change in the absorption spectrum with increasing the temperature (Figure 8a and Fig- 
ure S11). The amplitude of the band around $1572 \mathrm{eV}$ decreases in favour of the lower energy resonance around $1567 \mathrm{eV}$, similar to what was reported by Andrini et al. for annealed halloysite nanotubes. 11

To highlight the different components of the absorption spectrum, we draw inspiration from the work of Ildefonse et al. $\frac{6263}{6}$, who proposed a straightforward deconvolution with a set of Gaussian and a polynomial function, avoiding over-parameterization of the problem. The deconvolution consists of: ( $i)$ an arctangent step function for the single aluminum atom absorption component; (ii) a first Gaussian for the absorption of aluminum atoms in $\mathrm{Al}^{\mathrm{IV}}$ referred as A; (iii) a second Gaussian for the absorption of aluminum atoms in $\mathrm{Al}^{\mathrm{VI}}$ sites referred as $\mathrm{B}$ and $(i v)$ a last Gaussian function to improve the quality of the adjustment in the downward part of the absorption threshold referred as $\mathrm{C}$, related to multiple scattering effects (Figure $8 \mathrm{~b}) .62$ It is, however, difficult to discern the footprint of $\mathrm{Al}^{\mathrm{V}}$ environment, whose contribution is mixed with the one of the $\mathrm{Al}^{\mathrm{IV}}$ and $\mathrm{Al}^{\mathrm{VI}}$ sites. ${ }^{63} \mathrm{~A}$ multivariate analysis was also carried out in an effort to identify an $\mathrm{Al}^{\mathrm{V}}$ component different from $\mathrm{Al}^{\mathrm{IV}}$ and $\mathrm{Al}^{\mathrm{VI}}$ ones. ${ }^{64} \mathrm{No}$ evidence of a distinctive footprint of $\mathrm{Al}^{\mathrm{V}}$ environment has been found, in agreement with the first approach used. 63

The particularity of the procedure we put in place is that the refinement was carried out in parallel on the 500 XANES curves for all samples $\left(\mathrm{SW}, \mathrm{SW}_{\mathrm{b}}\right.$, DW and $\mathrm{DW}_{\mathrm{b}}$ ) as well as on references compounds (Figure 8c and Figure S12). The width and position of the Gaussians are optimized knowing that these parameters are the same over all curves while the amplitude of the Gaussian is refined curve by curve. Gibbsite and kaolinite are used here as six-fold aluminum model compounds with different local structure, the latter being formed by a gibbsitelike sheet linked to a Si tetrahedral one. ${ }^{63 \mid 65}$ In contrast, mullite corresponds to the final phase expected at the end of the heat treatment (Figure 3) with a relative amount of $\mathrm{Al}^{\mathrm{VI}}$ and $\mathrm{Al}^{\mathrm{IV}}$ sites. $\frac{66}{6}$ These references give us benchmarks on the evolution of $\mathrm{Al}$ coordination during thermal treatment.
As evidenced in Figure 8c, the local environment around aluminum atoms is altered during the dehydroxylation between 300 and $500{ }^{\circ} \mathrm{C}$ followed by a strong decrease of six-fold to fourfold (and/or five-fold) coordinated $\mathrm{Al}$ sites in agreement with our previous findings (see A contribution in Figure 8c). Interestingly, the amount of $\mathrm{Al}$ sites in the 'metaimogolite' phase obtained at $\mathrm{T}=800^{\circ} \mathrm{C}$ is closed to the expected structure of a mullite-type compound. The interest of the in-situ experiments compared to the ex-situ ones can be underlined here, as $\mathrm{Al}^{\mathrm{V}}$ coordination was observed after heat treatment treatment and cooling down of the sample by NMR. Comparison between the different samples reveals some differences in the transition temperature between SW and DW nanotubes while the initial organization of the nanotubes has a limited impact (Figure S12). SW INTs appear to be more sensitive to the thermal treatment, probably due to the presence of distorted octahedral environments in these samples. Finally, we aimed to assess kinetic effects right after dehydroxylation $\left(\mathrm{T}=500^{\circ} \mathrm{C}\right)$ and beyond $\mathrm{T}=700{ }^{\circ} \mathrm{C}$ during the atomic reorganization. For the latter, there is a slight evolution over time. However, kinetic effects do not appear predominant in the time range we investigated, whatever the samples (Figure S12).

\section{Proposed mechanism of structural reordering during thermal treat- ment}

Thanks to the deconvolution of the XANES spectra, we can identify five steps in the thermal transformation of the local structure around $\mathrm{Al}$ atoms as evidenced by insets in Figure $8 \mathrm{c}$. Below $\mathrm{T}=300^{\circ} \mathrm{C}$, aluminum remains only in $\mathrm{Al}^{\mathrm{VI}}$ form. Up to $500{ }^{\circ} \mathrm{C}$, the decrease in the coordination of $\mathrm{Al}$ atoms is related to dehydroxylation effects in accordance with TGA measurements. In the range $500-600{ }^{\circ} \mathrm{C}$, aluminum coordination remains stable. However, the proportion of $\mathrm{Al}^{\mathrm{VI}}$ sites drops significantly between 600 and $800^{\circ} \mathrm{C}$. Above $800^{\circ} \mathrm{C}$, the local structure around the aluminum atoms no longer evolves. Interestingly, the modification of aluminum 
a

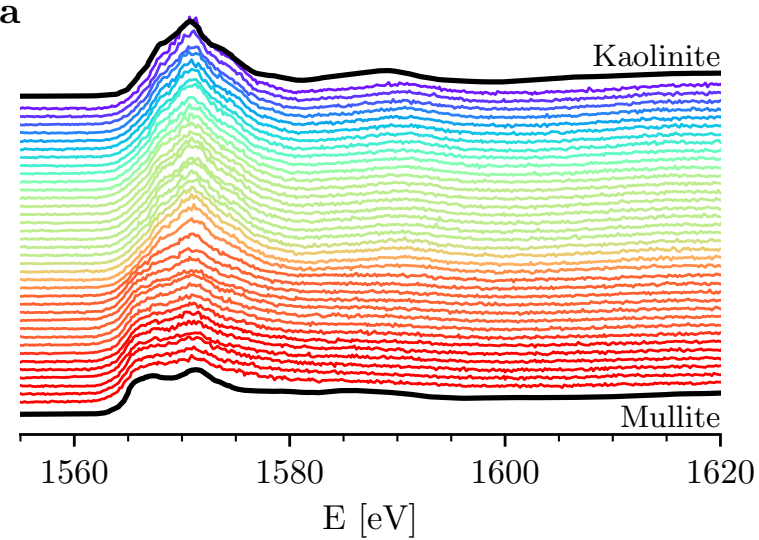

b

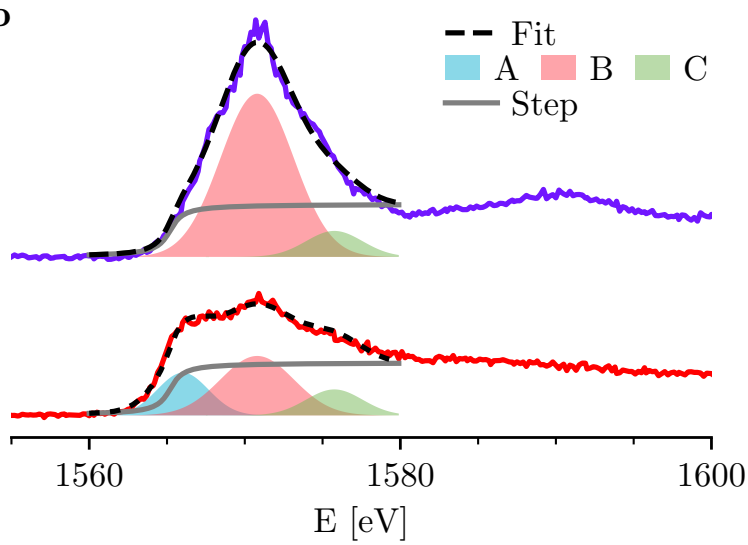

Temperature $\left[{ }^{\circ} \mathrm{C}\right]$

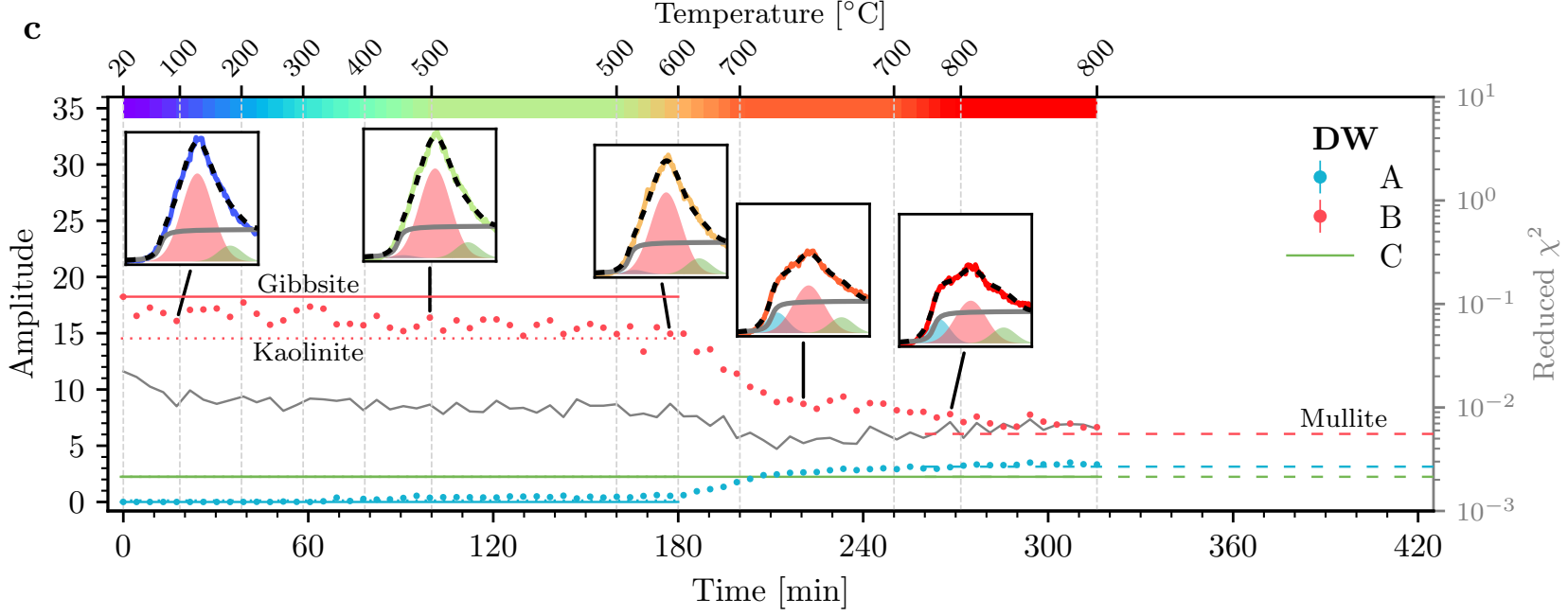

Figure 8: (a) Al K-edge XANES spectra series measured for a DW powder heated in-situ from ambient temperature (purple curve) to $800^{\circ} \mathrm{C}$ (red curve). (b) Typical refinement of the absorption threshold by 3 Gaussian components and a step-like function for the first (RT) and last XANES curve $\left(\mathrm{T}=800^{\circ} \mathrm{C}\right.$ ) of the series. (c) Amplitude of the first, the second and the third fitting Gaussians over heat treatment. The temperature and the time are displayed, respectively, on the top-axis and the bottom axis to reveal kinetic effect. The goodness of fit (reduced $\chi^{2}$ ) is drawn as grey curve. In addition, Gaussian components of the fitting procedure are given for different reference samples: gibbsite (full line), kaolinite (dotted line) and Si-mullite (dashed line).

coordination takes place in two separate steps but the dehydroxylation one contributes the least to the variation of the XANES spectra. The only possible explanation is that dehydroxylation leads to the formation of exclusively pentahedral aluminum $\mathrm{Al}^{\mathrm{V}}$, which contribute largely to the $\mathrm{B}$ component at approximately $1570 \mathrm{eV}$ in the deconvolution. The second step of modification of the XANES data $(\mathrm{T}=600$ $800^{\circ} \mathrm{C}$ ) reflects the formation of tetrahedral aluminum, as evidenced by the rise in component A at the expense of component B. Such modification of the structure takes place after the removal of hydroxyl groups, at constant mass (according to TGA data). Therefore, the appearance of $\mathrm{Al}^{\mathrm{IV}}$ must be accompanied by a local structural reordering with the formation of $\mathrm{Al}^{\mathrm{VI}}$ from $\mathrm{Al}^{\mathrm{V}}$ (Figure 9). Above $800^{\circ} \mathrm{C}$, we no longer observe any change in the coordination of $\mathrm{Al}$ atoms in the final structures.

Altogether, the combination of our observations leads us to propose a novel mechanism on the thermal transformation of $\mathrm{GeOH}$ imogolite nanotubes (Figure 9):

1. Dehydroxylation of INTs occurs between 300 and $500{ }^{\circ} \mathrm{C}$ with the formation of $\mathrm{Al}^{\mathrm{V}}$ to the detriment of $\mathrm{Al}^{\mathrm{VI}}$. Altogether, 
this leads to radial distortions of the nanotubes.

2. Between 500 and $600{ }^{\circ} \mathrm{C}$, dehydroxylated structures form a metaimogolite phase (Stage I) composed of $\mathrm{Al}^{\mathrm{V}}$ and $\mathrm{Al}^{\mathrm{VI}}$ sites.

3. For temperature in the range $600-800{ }^{\circ} \mathrm{C}$, a peculiar atomic reorganization takes place in the metaimogolite structure (Stage II), where the $\mathrm{Al}^{\mathrm{V}}$ disappear in favor of $\mathrm{Al}^{\mathrm{IV}}$ and $\mathrm{Al}^{\mathrm{VI}}$ by a possible atomic jump process $\left(\mathrm{Al}^{\mathrm{V}}+\mathrm{Al}^{\mathrm{V}} \longrightarrow\right.$ $\left.\mathrm{Al}^{\mathrm{VI}}+\mathrm{Al}^{\mathrm{IV}}\right)$.

4. The metaimogolite phase obtained at $\mathrm{T}=$ $800{ }^{\circ} \mathrm{C}$ remains relatively unaffected up to $\sim 1000^{\circ} \mathrm{C}$ (Stage III), where the elementary bricks $\mathrm{Al}^{\mathrm{VI}}$ and $\mathrm{Al}^{\mathrm{IV}}$ then reorganize into a mullite-type structure.

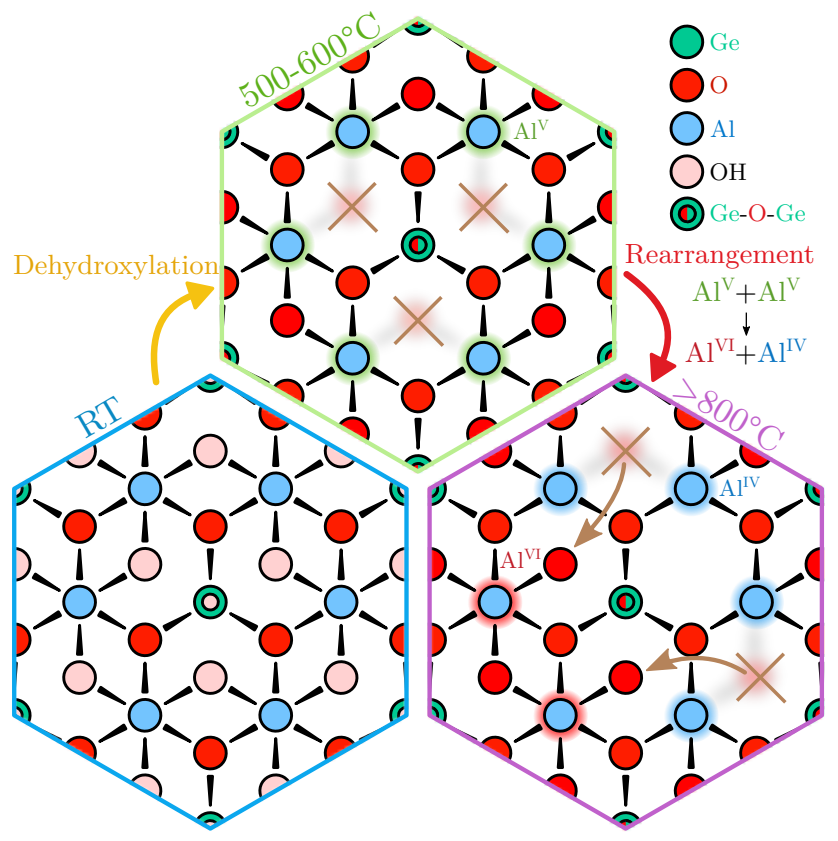

Figure 9: Scheme of dehydroxylation of imogolite nanotubes leading to a transformation of the octahedral configurations $\mathrm{Al}^{\mathrm{VI}}$ into $\mathrm{Al}^{\mathrm{V}}$ and $\mathrm{Al}^{\mathrm{IV}}$ configuration. The hexagons are associated with 2 unit cells of imogolite nanotube $2\left[(\mathrm{OH})_{3} \mathrm{Al}_{2} \mathrm{O}_{3} \mathrm{Ge}(\mathrm{OH})\right]$. The black lines indicate the interatomic bonds. Brown crosses show hydroxyl groups and bonds lost during dehydroxylation.

\section{Conclusion}

We investigated the thermal stability of SW and DW aluminogermanate INTs over a wide range of temperature. The combination of local techniques (IR, NMR and XAS spectroscopies) and of X-ray scattering allowed us to probe at the atomic scale the fate of $\mathrm{Al}$ and Ge atoms coordination during thermal treatment as well as the modification of the nanotube period and shape. The strength of this work is associated with the use of in-situ experiments. Beyond the dehydroxylation of the nanotubes and the re-crystallization into a mullite-type compound, our experiments provided new insights on the mechanisms involved in the formation of intermediate metaimogolite states formed in the range of temperature $\left(\mathrm{T}=300-800^{\circ} \mathrm{C}\right)$. After dehydroxylation, a first metaimogolite structure is formed by release of hydroxyl groups leading to $\mathrm{Al}^{\mathrm{V}}$ sites with important changes in the nanotube shape. Major atomic reorganization of this phase occur between 500 and $600{ }^{\circ} \mathrm{C}$ (stage II), probably by atomic jump processes. A decrease in periodicity of the metaimogolite compound is observed and the tubes have no longer circular cross-sections. The structure of the resulting metaimogolite phase (stage III) does not evolve until re-crystallization into a Ge-mullite type compound at $\mathrm{T}>900^{\circ} \mathrm{C}$. The understanding of the structural modifications of $\mathrm{GeOH}$ nanotubes as a function of temperature represents a benchmark for further studies concerning the reactivity of these metaimogolite phases.

Acknowledgement The authors acknowledge SOLEIL for provision of synchrotron radiation facilities under the approved proposals 20150188 \& 20160456. They thank the IRRAMAN platform of the University of Montpellier for providing access to the IR apparatus. The French Région Ile de France SESAME program is acknowledged for financial support $(700 \mathrm{MHz}$ NMR spectrometer). The authors would like to thank Gaël Monvoisin and Stéphanie Blanchardin for their help during ex-situ heat treatment of imogolite samples, Nicolas Trcera and Damien Roy for the development and the implementation of the furnace for flyscan XAS 
experiments on the LUCIA beamline, Baptiste Rigaud and Rozenn Le Parc for interesting exchanges with them on NMR or Raman spectroscopies. The authors wish to thank Dominique Thiaudière for his guidance during the EXAFS and DRX measurements carried out on the Diffabs beamline. Special thanks go to Valérie Briois for introducing them to the multivariate analysis of XAS spectra.

\section{Supporting Information Avail- able}

Additional thermogravimetric analysis, X-ray scattering, NMR measurements, EXAFS at the Ge K-edge and XANES at the Al K-edge for imogolite nanotubes with one or two walls, isolated or in bundles.

\section{References}

(1) Heller-Kallai, L. Developments in Clay Science; Elsevier, 2006; Vol. 1; pp 289308.

(2) Brindley, G. W.; Nakahira, M. Journal of the American Ceramic Society 1959, 42, 311-314.

(3) Bellotto, M.; Gualtieri, A.; Artioli, G.; Clark, S. M. Physics and chemistry of minerals 1995, 22, 207-217.

(4) Muraleedharan, M. G.; Asgar, H.; Mohammed, S.; Gadikota, G.; van Duin, A. C. T. Chemistry of Materials 2020, 32, 651-662.

(5) Daou, I.; Lecomte-Nana, G. L.; TessierDoyen, N.; Peyratout, C.; Gonon, M. F.; Guinebretiere, R. Minerals 2020, 10, 480.

(6) Lenarda, M.; Storaro, L.; Talon, A.; Moretti, E.; Riello, P. Journal of colloid and interface science 2007, 311, 537-543.

(7) Sabir, B. B.; Wild, S.; Bai, J. Cement and Concrete Composites 2001, 23, 441-454.
(8) Belver, C.; Bañares Muñoz, M. A.; Vicente, M. A. Chemistry of Materials 2002, 14, 2033-2043.

(9) Chandrasekhar, S.; Pramada, P. N. Microporous and Mesoporous Materials 2008, 108, 152-161.

(10) Yuan, P.; Tan, D.; Annabi-Bergaya, F.; Yan, W.; Fan, M.; Liu, D.; He, H. Clays and Clay Minerals 2012, 60, 561-573.

(11) Andrini, L.; Moreira Toja, R.; Conconi, M. S.; Requejo, F. G.; Rendtorff, N. M. Journal of Electron Spectroscopy and Related Phenomena 2019, 234, 19-26.

(12) Du, P.; Yuan, P.; Liu, D.; Wang, S.; Song, H.; Guo, H. Applied Clay Science 2018, 158, 211-218.

(13) Yoshinaga, N.; Aomine, S. Soil Science and Plant Nutrition 1962, 8, 22-29.

(14) Mukherjee, S.; Bartlow, V. M.; Nair, S. Chemistry of Materials 2005, 17, 49004909 .

(15) Levard, C.; Rose, J.; Thill, A.; Masion, A.; Doelsch, E.; Maillet, P.; Spalla, O.; Olivi, L.; Cognigni, A.; Ziarelli, F.; et al., Chemistry of Materials 2010, 22, 24662473 .

(16) Yucelen, G. I.; Choudhury, R. P.; Vyalikh, A.; Scheler, U.; Beckham, H. W.; Nair, S. Journal of the American Chemical Society 2011, 133, 5397-5412.

(17) Kang, D.-Y.; Brunelli, N. A.; Yucelen, G. I.; Venkatasubramanian, A.; Zang, J.; Leisen, J.; Hesketh, P. J.; Jones, C. W.; Nair, S. Nature communications 2014, 5, 1-9.

(18) Amara, M. S.; Paineau, E.; Rouzière, S.; Guiose, B.; Krapf, M.-E. M.; Taché, O.; Launois, P.; Thill, A. Chemistry of Materials 2015, 27, 1488-1494. 
(19) Paineau, E.; Krapf, M.-E. M.; Amara, M.S.; Matskova, N. V.; Dozov, I.; Rouzière, S.; Thill, A.; Launois, P.; Davidson, P. Nature Communications 2016, 7, 10271.

(20) Thill, A.; Picot, P.; Belloni, L. Applied Clay Science 2017, 141, 308-315.

(21) Picot, P.; Liao, Y.; Barruet, E.; Gobeaux, F.; Coradin, T.; Thill, A. Langmuir 2018, 34, 13225-13234.

(22) Monet, G.; Amara, M. S.; Rouzière, S.; Paineau, E.; Chai, Z.; Elliott, J. D.; Poli, E.; Liu, L.-M.; Teobaldi, G.; Launois, P. Nature communications 2018, 9, 1-9.

(23) Paineau, E. Applied Sciences 2018, 8, 1921.

(24) Cradwick, P. D. G.; Farmer, V. C.; Russell, J. D.; Masson, C. R.; Wada, K.; Yoshinaga, N. Nature Physical Science 1972, 240, 187-189.

(25) Paineau, E.; Launois, P. Nanomaterials from Clay Minerals; Elsevier, 2019; pp 257-284.

(26) Maillet, P.; Levard, C.; Larquet, E.; Mariet, C.; Spalla, O.; Menguy, N.; Masion, A.; Doelsch, E.; Rose, J.; Thill, A. Journal of the American Chemical Society 2010, 132, 1208-1209.

(27) Thill, A.; Maillet, P.; Guiose, B.; Spalla, O.; Belloni, L.; Chaurand, P.; Auffan, M.; Olivi, L.; Rose, J. Journal of the American Chemical Society 2012, 134, 3780-3786.

(28) Rouzière, S.; Amara, M. S.; Paineau, E.; Launois, P. Developments in Clay Science; Elsevier, 2016; Vol. 7; pp 254-278.

(29) Donkai, N.; Miyamoto, T.; Kokubo, T.; Tanei, H. J. Mater. Sci. 1992, 27, 61936196.
(30) Farmer, V. C.; Adams, M. J.; Fraser, A. R.; Palmieri, F. Clay Miner. 1983, 18, 459-472.

(31) Van der Gaast, S. J.; Wada, K.; Wada, S.I.; Kakuto, Y. Clays and Clay Minerals 1985, 33, 237-243.

(32) MacKenzie, K. J. D. Clays and Clay Minerals 1989, 37, 317-324.

(33) Zanzottera, C.; Vicente, A.; Armandi, M.; Fernandez, C.; Garrone, E.; Bonelli, B. J. Phys. Chem. C 2012, 116, 23577-23584.

(34) Kang, D.-Y.; Zang, J.; Wright, E. R.; McCanna, A. L.; Jones, C. W.; Nair, S. Acs Nano 2010, 4, 4897-4907.

(35) Hatakeyama, M.; Hara, T.; Ichikuni, N.; Shimazu, S. Bulletin of the Chemical Society of Japan 2011, 84, 656-659.

(36) Wilson, M. A.; Wada, K.; Wada, S. I.; Kakuto, Y. Clay minerals 1988, 23, 175190.

(37) da Silva, M. C.; dos Santos, E. C.; Lourenço, M. P.; Gouvea, M. P.; Duarte, H. A. Frontiers in Materials 2015, 2, 16.

(38) Antoni, M.; Rossen, J.; Martirena, F.; Scrivener, K. Cement and Concrete Research 2012, 42, 1579-1589.

(39) Zapała-Sławeta, J. Materials and Structures 2017, 50.

(40) Amara, M.-S.; Paineau, E.; BaciaVerloop, M.; Krapf, M.-E. M.; Davidson, P.; Belloni, L.; Levard, C.; Rose, J.; Launois, P.; Thill, A. Chemical Communications 2013, 49, 11284-11286.

(41) Paineau, E.; Amara, M. S.; Monet, G.; Peyre, V.; Rouzière, S.; Launois, P. The Journal of Physical Chemistry C 2017, 121, 21740-21749.

(42) Paineau, E.; Monet, G.; Peyre, V.; Goldmann, C.; Rouzière, S.; Launois, P. Langmuir 2019, 
(43) Amara, M. S.; Rouzière, S.; Paineau, E.; Bacia-Verloop, M.; Thill, A.; Launois, P. The Journal of Physical Chemistry C 2014, 118, 9299-9306.

(44) Paineau, E.; Rouzière, S.; Monet, G.; Diogo, C. C.; Morfin, I.; Launois, P. Journal of Colloid and Interface Science $\mathbf{2 0 2 0}$,

(45) Liao, Y.; Picot, P.; Lainé, M.; Brubach, J.B.; Roy, P.; Thill, A.; Le Caër, S. Nano Research 2018, 4759-4773.

(46) Amara, M. S. Nanotubes d'imogolite et propriétés de l'eau confinée : organisation, structure et dynamique. Theses, Université Paris Sud - Paris XI, 2014.

(47) Massiot, D.; Fayon, F.; Capron, M.; King, I.; Le Calvé, S.; Alonso, B.; Durand, J.-O.; Bujoli, B.; Gan, Z.; Hoatson, G. Magnetic Resonance in Chemistry 2002, 40, 70-76.

(48) Ravel, B.; Newville, M. Journal of Synchrotron Radiation 2005, 12, 537-541.

(49) Vantelon, D.; Trcera, N.; Roy, D.; Moreno, T.; Mailly, D.; Guilet, S.; Metchalkov, E.; Delmotte, F.; Lassalle, B.; Lagarde, P.; et al., Journal of Synchrotron radiation 2016, 23, 635-640.

(50) Newville, M. et al. LMfit: Non-Linear Least-Square Minimization and CurveFitting for Python. 2019.

(51) Liao, Y.-Y.; Picot, P.; Brubach, J.-B.; Roy, P.; Thill, A.; Le Caer, S. The Journal of Physical Chemistry C 2019, 123, 19768-19777.

(52) Monet, G.; Paineau, E.; Chai, Z.; Amara, M. S.; Orecchini, A.; JiménezRuiz, M.; Ruiz-Caridad, A.; Fine, L.; Rouzière, S.; Liu, L.-M.; et al., Nanoscale Advances 2020, 2, 1869-1877.

(53) Voll, D.; Lengauer, C.; Beran, A.; Schneider, H. European Journal of Mineralogy 2001, 13, 591-604.
(54) Wada, S.-i.; Wada, K. Clays and Clay Minerals 1982, 30, 123-128.

(55) Bishop, J. L.; Ethbrampe, E. B.; Bish, D. L.; Abidin, Z. L.; Baker, L. L.; Matsue, N.; Henmi, T. Clays and Clay Minerals 2013, 61, 57-74.

(56) Voll, D.; Angerer, P.; Beran, A.; Schneider, H. Vibrational Spectroscopy 2002, 30, 237-243.

(57) Cambedouzou, J.; Chorro, M.; Almairac, R.; Noé, L.; Flahaut, E.; Rols, S.; Monthioux, M.; Launois, P. Physical Review B 2009, 79, 195423.

(58) Goodman, B. A.; Russell, J. D.; Montez, B.; Oldfield, E.; Kirkpatrick, R. J. Physics and Chemistry of Minerals 1985, 12, 342-346.

(59) Yucelen, G. I.; Choudhury, R. P.; Leisen, J.; Nair, S.; Beckham, H. W. The Journal of Physical Chemistry C 2012, 116, 17149-17157.

(60) Woessner, D. E. American Mineralogist 1989, 74, 203-215.

(61) Smith, M. E. Applied Magnetic Resonance 1993, 4, 1-64.

(62) Ildefonse, P.; Kirkpatrick, R. J.; Montez, B.; Calas, G.; Flank, A. M.; Lagarde, P. Clays and Clay Minerals 1994, 42, 276-287.

(63) Ildefonse, P.; Cabaret, D.; Sainctavit, P.; Calas, G.; Flank, A.-M.; Lagarde, P. Physics and Chemistry of Minerals 1998, 25, 112-121.

(64) Cassinelli, W. H.; Martins, L.; Passos, A. R.; Pulcinelli, S. H.; Santilli, C. V.; Rochet, A.; Briois, V. Catalysis Today 2014, 229, 114-122.

(65) Kato, Y.; Shimizu, K.-i.; Matsushita, N.; Yoshida, T.; Yoshida, H.; Satsuma, A.; Hattori, T. Physical Chemistry Chemical Physics 2001, 3, 1925-1929. 
(66) Schneider, H.; Schreuer, J.; Hildmann, B.

Journal of the European Ceramic Society 2008, 28, 329-344. 


\section{Graphical TOC Entry}

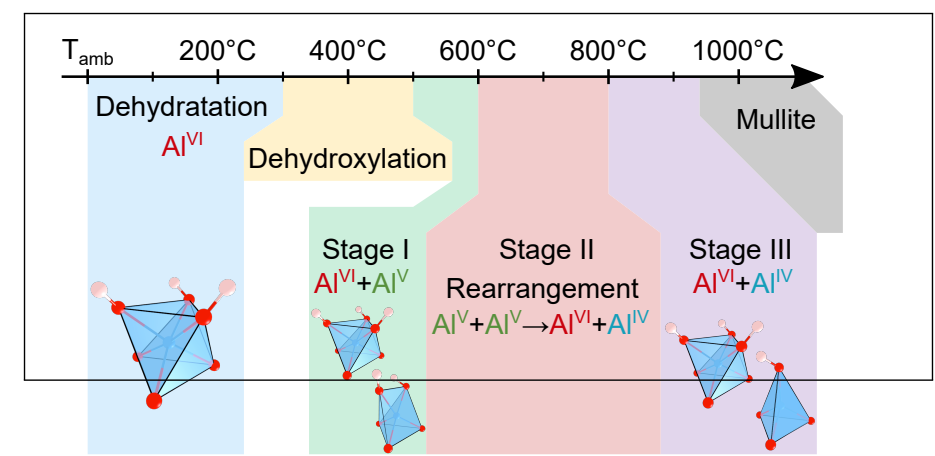

